\title{
United Nations shelves action on indoor hazards
}

A United Nations (UN) meeting has failed to agree on an action plan to deal with indoor air pollution - the range of hazards related to cooking indoors that is thought to kill more people every year in poor countries than malaria.

Despite two weeks of negotiations in New York, the UN Commission on Sustainable Development was unable to ratify a draft communiqué on indoor pollution and other developmental issues that were up for discussion. But activists say the very fact that the discussion took place represents valuable progress in acknowledging the scale of the pollution problem.

\section{"The problem of} indoor air pollution has been basically invisible."

At the end of a fractious meeting that culminated in the election of the Zimbabwean environment minister, Francis Nhema, to chair the commission, representatives from Switzerland and the European Union (EU) rejected the draft communiqué, saying that its vacuous content would threaten past agreements and contained no goals that would spur action on a number of key issues.

"In previous discussions, the problem of indoor air pollution has been basically invisible, perhaps because it is a situation that affects mainly women," says Maria Arce Moreira, a policy adviser to Practical Action, a British pressure group that works on poverty issues. "It's important that it is finally recognized as a problem, but the proposed actions to deal with it are not enough."

Around half of the world's population cooks on stoves that burn biomass such as wood, crop residues or dung, development specialists say. According to estimates from the World Health Organization (WHO), smoke emitted by traditional cookers kills 1.6 million people each year, most of them women and children (WHO Indoor Air Pollution: National Burden of Disease Estimates; 2007).

Researchers predict that if these trends continue, in Africa alone indoor air pollution will kill 10 million people by 2030. Of these deaths, up to 3.7 million could be saved by switching to petroleum-based fossil fuels such as kerosene (R. Bailis et al. Science 308, 98-103; 2005).

Lung cancer, pneumonia and acute lowerrespiratory infections are prevalent as a result of constant exposure to carbon monoxide, particulates, hydrocarbons and carcinogens such as formaldehyde and benzene that are contained in cooking smoke.

Activist groups, including Practical Action,

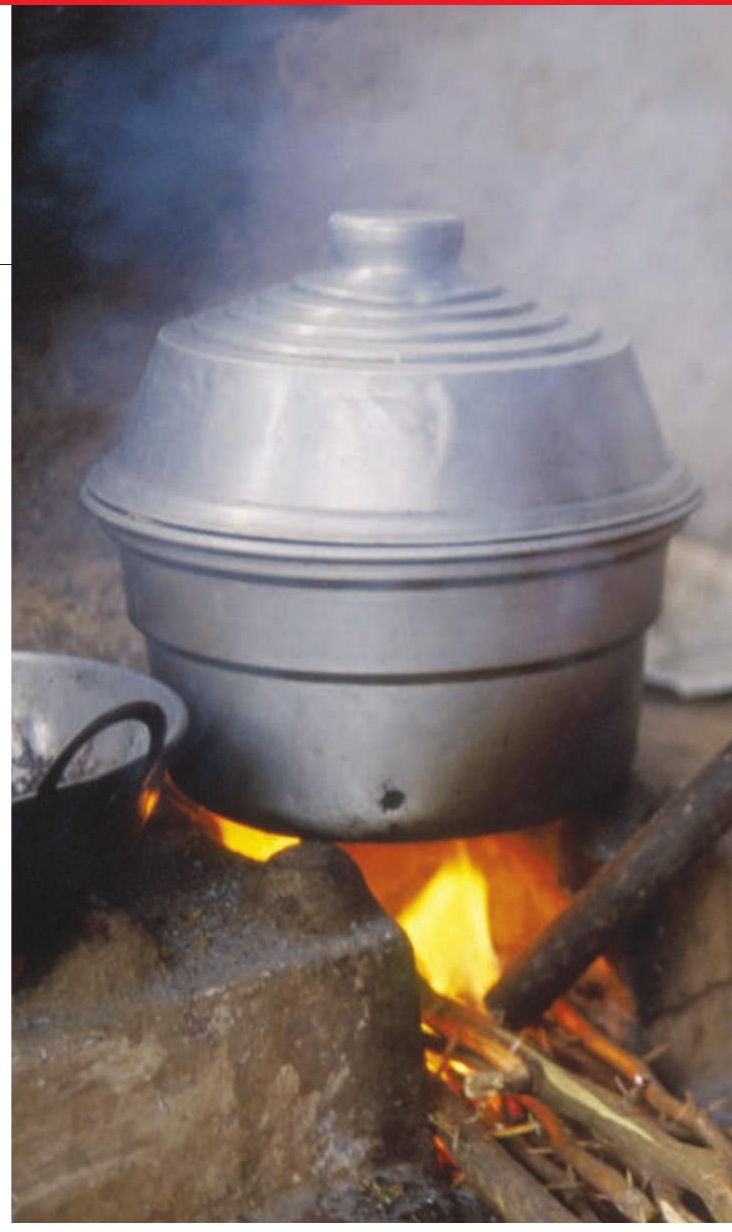

have previously called on governments to adopt firm measures to halve the number of people cooking with traditional fuels. But with fossil-fuel prices at historic highs, and most of the world's poorest people using wood-burning stoves, there is little appetite for such measures.

Nonetheless, EU representatives wanted the UN commission to ask nations and regions to set appropriate targets, "because without targets you cannot easily review these issues", says Natascha Beinker, a policy adviser at the

\section{Modellers seek reason for low retraction rates}

Computer scientists at Columbia University in New York have used a mathematical model to estimate the number of flawed scientific papers that go unretracted, and its relation to journal impact factors.

In correspondence published in EMBO Reports (M. Cokol et al. EMBO Rep. 5, 422-423; 2007), the researchers find that fewer papers are retracted by journals with low impact factors. But their model raises as many questions as it answers, say specialists in scientific publishing, some of whom argue that it greatly oversimplifies the issues.

\author{
Murat Cokol and his colleagues \\ at the biomedical-informatics \\ department at Columbia \\ downloaded data for 9.4 million \\ articles published between \\ 1950 and 2004 from PubMed, \\ an index of biomedical and \\ general scientific literature. \\ They identified 596 retracted \\ articles - flagged up as such \\ in PubMed - and found some \\ striking relationships between the \\ numbers of retractions and the \\ impact factors of the journals that \\ had published them. \\ Journals with high impact \\ factors retract more papers, and
}

low-impact journals are more likely not to retract them, the study finds. It also suggests that highand low-impact journals differ little in detecting flawed articles before they are published.

Finally, the authors ran a model to estimate how many articles should have been retracted, and came up with 10,000 in a bestcase scenario and more than 100,000 in a worst-case one. Most of the papers that needed to be retracted were published in lowimpact journals.

The Cokol study was not peerreviewed. Aviv Bergman, director of the Center for Computational Genetics and Biological Modeling at Stanford University in California, says that the researchers' modelling techniques are sound, but that he isn't in a position to judge their input data.

But scientists and editors familiar with retraction issues are sceptical of the quality of the model's input data. Theoretical modelling exercises will generate bad results if the input data are flawed, says Drummond Rennie, deputy editor of the Journal of the American Medical Association, and a medical researcher at the 


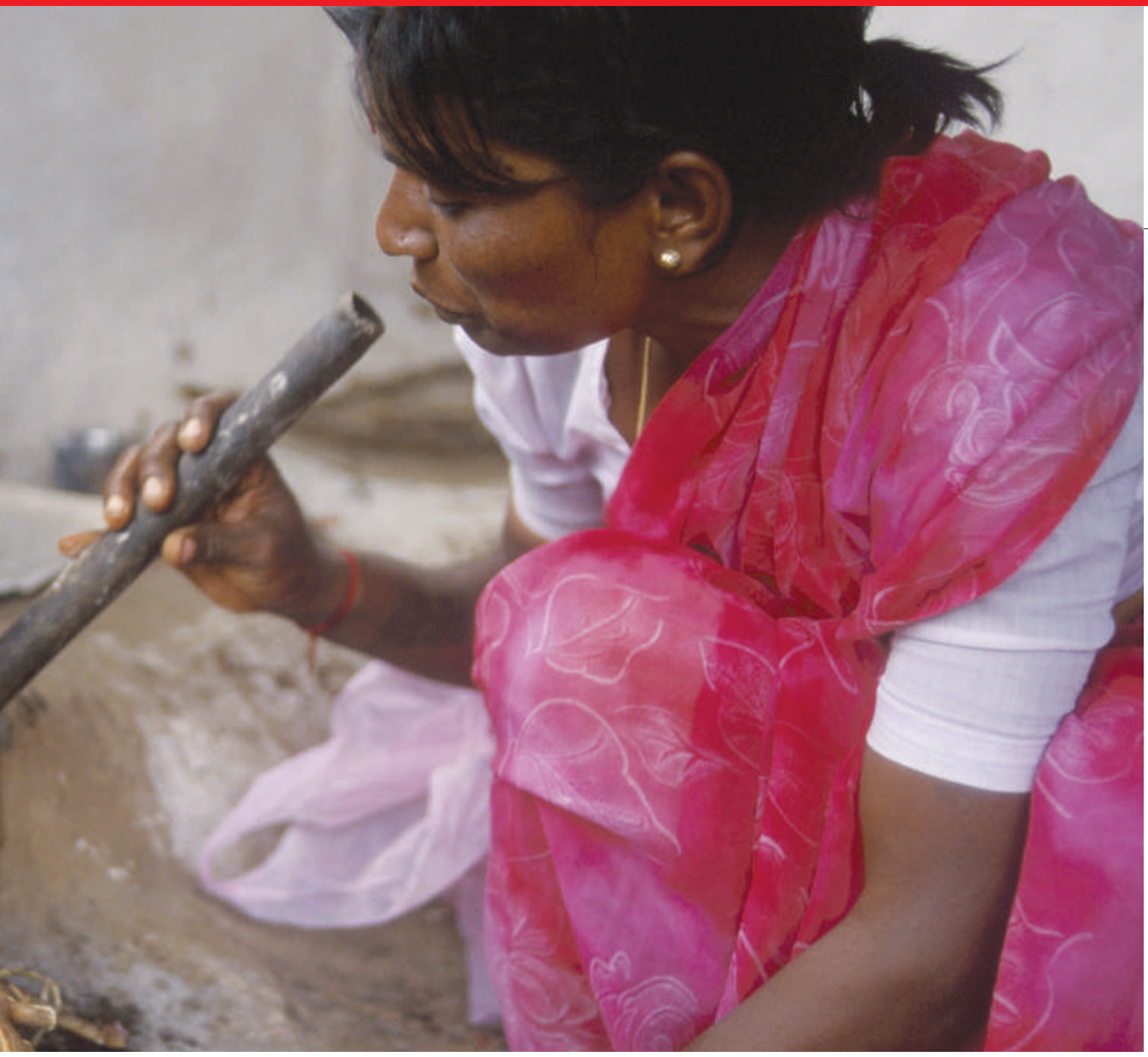

Cooking with fire: wood-burning stoves are a major source of indoor pollution.

German ministry for economic cooperation and development, who attended the meetings.

EU representatives also called for a commitment to switching to cleaner biofuels, and to delivering financial aid and addressing the health risks from indoor cooking, "but there was not total commitment for this", Beinker adds.

"The Americans and Australians seem less willing to accept that there is a policy issue," says Andrew Scott, policy director for Practical Action. African and South American nations, which see environmental rules as restraints on their economic development, agreed that the issue was not a political one and blocked the EU move.

Peter Davies, an energy adviser to the UK Department for International Development, who was also at the meetings, argues that

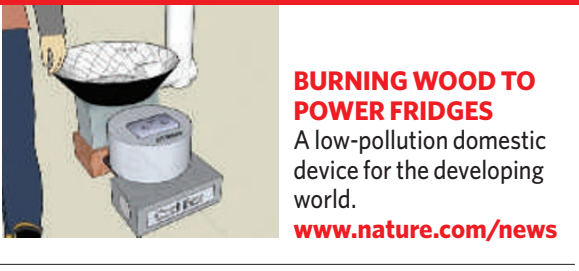

progress remains possible without firm targets. "Goals and targets are not something developed countries can push on. These are issues that national governments need to decide for themselves with their own national-development and poverty-reduction plans."

This year's meeting of the sustainable-development commission concentrated on four main issues - energy, industrial development, air pollution and climate change. The most contentious debate was fuelled by discussions on acceptable sources of energy.

"The EU and First World groups tended to be influenced by environmental issues, whereas the G77 [the developing nations] seemed to take a much harder-nosed look at what they need for their economic development," says Davies.

The lack of consensus means that rather than producing a final summary agreed by all countries, this year's chair, Abdullah bin Hamad alAttiyah of Qatar, will issue a text that merely lists the points discussed.

"The final text will be very watered down now," says Arce Moreira. "We do not envisage support for energy issues related to indoor air pollution, such as addressing access to modern energy for the poor."

But Davies says that what matters is that the hitherto obscure issue of indoor pollution is gradually raising its political profile. "Whatever the chair's summary says will be pretty bland. It has been negotiated to the lowest common denominator. But I think it will be a mistake to look at the chair's summary and say this is it," he says. "The process and the debate it generates has value in itself."

Narelle Towie
Institute for Health Policy Studies, at the University of California, San Francisco.

Although the number of retracted articles is probably only the tip of the iceberg in terms of the number that should have been retracted, the model - based on journal impact factor and number of retractions - is too simplistic to capture the complex reality of the issues affecting the size and nature of the hidden part, Rennie says.

The model clumps data from 1950 to 2004 , for example, whereas trends are likely to be affected by the fact that the United States first introduced official policies on research misconduct twenty years ago, and that other nations did so even later, says Rennie.

Experience also shows that retraction figures are skewed by the fact that once misconduct is detected in one article by a researcher, dozens of articles by

"No one has much clue what the real number of retractions should be."

the same author often need to be retracted. "Digging into the data behind all these other articles is a truly monumental task, but until it's done, no one has much clue what the real number of retractions should be," says Rennie.

Impact factor alone is also a very broad yardstick, says one scientific-literature specialist at PubMed, who points out that the impact factors of individual articles vary widely, even when they are in the same journal. Other models could also be made to fit the data with potentially very different outcomes, he says. High-impact journals might attract flawed papers, he speculates, simply because they publish cutting-edge research, in which competition and time pressure may favour both errors and misconduct.

In the correspondence, Cokol argues that the larger number of retractions in high-impact journals reflects the fact that they receive more scrutiny. But Sandra Titus, director of intramural research at the US Office of Research Integrity in Rockville, Maryland, says that's too simple a verdict. "It's only part of the issue," she says, adding that "legal barriers to retraction are so awkward that many journals simply pass rather than face the hassle."

Cokol defends his approach as a valid one to start exploring data on retraction. "All models are wrong, but some are useful," he says. "Our model certainly does not capture the reality in full, and no model does. But it captures certain aspects and gives a general direction on how to understand the issue better."

Declan Butler and Jenny Hogan 